\title{
A PSICOLOGIA ESCOLAR CRÍTICA E SEU COMPROMISSO SOCIAL
}

Kairon Pereira de Araújo Sousa

Universidade Federal do Piauí - UFPI

\section{Publicação}

Martínez, A. M. (Ed.). (2015). Psicologia escolar e compromisso social: Novos discursos, novas práticas. $3^{a}$ Ed, Campinas, SP: Editora Alínea.

\section{RESENHA}

O livro Psicologia Escolar e Compromisso Social: Novos Discursos, Novas Práticas é formado por um copilado de textos de variados autores, membros do Grupo de Psicologia Escolar/Educacional da Associação de Pesquisa e PósGraduação em Psicologia (ANPEPP). Organizado por Albertina Mitjáns Martínez, professora associada da Universidade de Brasília (UNB), o livro é estruturado em três partes: (1a) O psicólogo escolar: novas formas de atuação (integrando os capítulos 1 a 4); (2a) O Psicólogo Escolar perante os Discursos e as Práticas de Inclusão (capítulos 5 ao 7); (3a) O Psicólogo Escolar em Contextos Diferenciados (capítulos 8 ao 12).

No primeiro capítulo do livro, intitulado $A$ escola amordaçada e o compromisso do psicólogo com este contexto, escrito por Raquel Souza Lobo Guzzo, a autora reflete sobre a escola e o processo educativo em uma sociedade capitalista e, de que forma, tendo em vista este contexto, o psicólogo pode balizar a sua atuação.

Guzzo aponta os impactos da ideologia capitalista no processo de ensino formal (escolar), considerando o contexto de coisificação, ao qual estamos imersos, onde tudo se reduz a bens de consumo, produtos ou mercadorias, incluindo-se a educação. A escola, enquanto instituição de formação do sujeito, reverbera a lógica da dominação, por meio de ensino domesticador, alienante, amordaçado e descontextualizado, incapaz de problematizar o quadro social ou mesmo refletir de forma crítica sobre o mesmo. Essa situação reflete o descaso do poder público (posto sob os interesses das classes economicamente dominantes) com uma forma de educação emancipadora, difundindo ensino pragmático como uma justificativa para a acomodação. Nesse sentido, a escola é posta como uma instituição voltada para a adaptação do sujeito ao meio. Ela contribui para o processo de alienação recorrendo a um currículo estéril, burocrático e pouco voltado para a conscientização e libertação. Ademais, conforme a autora, inclui, para excluir.

Relativo a isso, Guzzo também discute a escola como um espaço de violência simbólica e institucionalizada, criadora de opressão e patologização. 
Recorrendo a Martín-Baró, apresenta o termo "terrorismo na educação" para expressar a situação de violência, esteriotipação e ideologização das desigualdades (bons, maus alunos), etc., que se traduzem em consequências diversas, como as psicopatologias.

Diante desse quadro, existem dois posicionamentos, segundo a autora, que o psicólogo escolar pode assumir: (1) atuar como legitimador das desigualdades, da violência e exclusão, culpabilizando o aluno, reproduzindo, através de sua práxis a lógica de dominação; ou (2) a partir de uma visão crítica das dinâmicas das forças de poder no espaço escolar, buscar contribuir para a construção de um locus educativo, permita o exercício crítico, a liberdade, a autonomia, o respeito e o desenvolvimento daqueles que estão vivenciando o processo de escolarização, possibilitando a compreensão de como as políticas sociais e a ideologia dominante afetam o cotidiano de uma comunidade, com a qual a escola lida. Isto só é possível quando o profissional dispõe de referencial teórico crítico que lhe possibilite refletir, questionar e a propor intervenções para tal realidade. Sendo assim, Guzzo indica como fonte relevante a ser inserida no repertório teórico do psicólogo escolar: a psicologia da libertação de Martín-Baró.

Violência na Escola: o psicólogo escolar na fronteira da política educacional é o título do capítulo dois. Nele, Herculano Ricardo Campos e colaboradores abordam a temática da violência enquanto um fenômeno psicossocial, presente tanto nas escolas frequentadas pelo público de baixa renda, como em instituições de ensino voltadas para as elites.

Os autores relatam dados de uma pesquisa realizada na cidade de Natal RN, em instituições de ensino públicas e privadas, que aponta para um quadro de violência institucionalizada. Nesse contexto, discute-se a relevância do psicólogo escolar nas escolas do ensino básico, sendo a violência na escola uma das demandas ao qual o profissional da psicologia poderia contribuir para resolução. Portanto, nesse capítulo, os autores intentam justificar e/ou reivindicar a presença do psicólogo nos sistemas público de ensino.

No capítulo três, Práticas Emergentes em Psicologia Escolar: nova ética, novos compromissos, Alacir Villa Valle Cruces faz uma análise de alguns resultados de uma pesquisa longitudinal realizada no Instituto de Psicologia da USP, com egressos do curso de psicologia, objetivando verificar se as práticas conduzidas pelos profissionais que afirmaram atuar na área educacional se coadunavam com o paradigma de uma psicologia crítica.

Por meio do exame dos dados, a autora concluiu que, apesar da existência de atividades tradicionais em psicologia escolar, como o psicodiagnóstico de estudantes através de testes psicométricos, a maioria das ações desempenhadas por profissionais que atuam como psicólogos escolares reflete uma nova ética ou paradigma nesse campo, apontando para o compromisso da psicologia com a construção de um espaço educativo mais favorável ao processo de ensinoaprendizagem. 
No quarto capítulo, O Psicólogo Escolar e a Alfabetização, Maria Regina Maluf, por meio de um relato de experiência, descreve sua atuação como psicóloga escolar no acompanhamento de uma criança encaminhada pela escola para atendimento médico-psicológico, por não desenvolver habilidades de leitura e escrita. A autora discute o papel do psicólogo escolar frente ao processo de ensino-aprendizagem da língua escrita nos anos iniciais da escolarização de crianças. Diante da questão, Maluf reforça a importância, da apropriação de conhecimentos da área educacional, que permita ao psicólogo escolar compreender os processos envolvidos na aquisição da linguagem escrita e propor intervenções adequadas a esta problemática ou queixa escolar.

Inclusão escolar: desafios para os psicólogos é o título que nomeia o capítulo cinco. Neste, Albertina Mitjáns Martínez discute a inclusão escolar e destaca os desafios que esse processo impõe ao psicólogo. A autora salienta a distorção existente em relação ao conceito de inclusão escolar, recorrentemente associado ao processo de inserção de alunos com necessidades especiais ao ensino regular. Deste modo, demonstra que essa concepção simplista e restritiva, a respeito da inclusão escolar, provoca limitações. Em primeiro lugar, porque reduz a inclusão a um grupo restrito de alunos, os portadores de necessidades educacionais especiais, desconsiderando outros grupos excluídos, como negros, pobres, trabalhadores de rua, entre outros. Em segundo lugar, a proposta de mudança na escola, tendo em conta essa definição reducionista, deixa de operacionalizar-se de forma ampla permitindo a inclusão real desses alunos, que representam a maioria nas salas de aula.

Sem pretender esgotar a discussão sobre a temática, a autora elenca três desafios, colocados pela inclusão escolar, para os psicólogos: (1) as mudanças de representação e concepções - para incluir, de acordo com Martínez, é necessária uma mudança de concepção, sobretudo considerando a sala de aula como um espaço diversificado, e a subjetividade de cada sujeito, ou seja, o processo de aprendizagem é singularizado, o que implica em uma personalização do ensino. Este construído tendo como referência apenas um determinado grupo de alunos (padronização), ocasiona a exclusão; (2) o trabalho em relação à subjetividade social da escola - a autora pontua que, para o processo de inclusão se concretizar nos espaços escolares, é necessário uma mudança na representação sobre inclusão escolar, não apenas de professores ou do processo pedagógico, mas na instituição como um todo, de modo que as subjetividades e diferenças sejam aceitas e respeitadas, tendo o psicólogo papel relevante nessa tarefa de mudança de concepção; (3) o compromisso social - a autora ressalta que a atuação do psicólogo escolar, diante do desafio da inclusão escolar, através de uma ação comprometida com o social e com a transformação dessa realidade, diz respeito a visão de mundo, a motivação e compromisso em querer desenvolver uma ação que engendre mudanças que impactem, sobretudo, os desfavorecidos. 
O capítulo seis trata do seguinte assunto: O Psicólogo nas Redes de Serviços de Educação Especial: desafios em face da inclusão. Nele, Alexandra Ayach Anache aborda os desafios em relação à inclusão, voltando-se para a educação especial. Para essa empreitada, a autora, incialmente, situa-nos a respeito do conceito de necessidades especiais e, recorrendo ao itinerário histórico de encontro da psicologia com a educação, faz menção às formas tradicionais de atuação em psicologia escolar, que ao longo dos anos legitimaram a discriminação e a segregação, através de práticas voltadas para o diagnóstico, reforçando a tese do aluno-problema. Nesse ínterim, Anache também salienta a lacuna existente no currículo de formação do psicólogo, que se expressa pela ausência de disciplinas que o instrumentalize para atuar na política de educação inclusiva. A autora apresenta um estudo realizado com psicólogos atuantes em equipes de atendimento escolares com necessidades especiais, no estado do Mato Grosso do Sul, pontuando a existência de uma situação contraditória face à atuação do profissional nas redes de serviços de educação especial, uma vez que se por um lado a sua práxis deve-se voltar para promover a efetivação do processo de inclusão, possibilitando o desenvolvimento das potencialidades dos estudantes, por outro lado, o psicólogo tenta responder a esses desafios por meio de princípios tradicionais, o que implica a necessidade de reconfiguração dessas práticas, sobretudo, tendo como referência a literatura comprometida com o social.

No capítulo sete, Psicologia Escolar e Educação Inclusiva: novas práticas de atendimento às queixas escolares, Marisa Maria Brito da Justa Neves e Ana Cláudia Almeida Machado apresentam ao público leitor uma nova perspectiva de atuação em psicologia escolar, tendo em vista o seu papel e/ou compromisso com a transformação da realidade educacional: os Procedimentos de Avaliação e Intervenção das Queixas Escolares-PAIQUE que se constitui como uma proposta diferente (do modo tradicional) de avaliação e intervenção das queixas escolares.

O PAIQUE apresenta cinco níveis: o encontro com professor; análise da história escolar do aluno; o encontro com a família; o encontro individual com o aluno e o encontro com o aluno nos grupos de atendimento. As autoras relatam os atendimentos realizados por profissionais que participaram do curso de Extensão nas Práticas de Atendimento às Queixas Escolares ofertado pela UNB, utilizando o PAIQUE. Os resultados demonstraram a eficiência do PAIQUE, sobretudo, por incluir, no processo de escuta e intervenção, o professor, normalmente, omitido nas ações voltadas à queixa escolar.

Celia Vectore, no capítulo oito Estratégias Mediacionais: possibilidades de inserção do psicólogo escolar/educacional em abrigos, discute algumas propostas de programas (o MISC - que tem como base os pressupostos de Vigotski - e APA - fundamentado na teoria de Bronfenfrenner) que podem ser incorporados pelos psicólogos escolares/educacionais, que atuam como mediadores em instituições 
de abrigo infantis, contribuindo para subsidiar a sua práxis nesse espaço de atuação.

O capítulo nove, escrito por Maria Helena N. Mira, Rachel M. M. Tardin e Elaine M. Pedroza, trata das Alternativas de Atuação da Psicologia Escolar Junto à Terceira Idade. Inicialmente as autoras discutem sobre o processo de envelhecimento, considerando seus aspectos biopsicossociais. Deste modo, aborda-se a noção de velhice como uma construção social. São mencionadas algumas alterações vivenciadas na terceira idade, sobretudo as de memória, elencando-se os fatores relacionados à diminuição da capacidade de absorver e processar as informações.

Discute-se também a possibilidade de ensino voltado para a terceira idade e os programas educativos delineados a esse público. Nesses aspectos, as autoras destacam o papel do psicólogo escolar no processo de prevenção, diagnóstico e acompanhamento aos idosos em programas educativos. O capítulo é finalizado com a apresentação das ações promovidas pelo Programa de Ativação Cerebral Criativo (PACC) da PUC-RJ com idosos.

No capítulo dez, Formação e Atuação do Psicólogo Escolar da Rede Pública de Ensino do Distrito Federal: panorama atual e perspectivas futuras, Sylvia Regina C. Magalhaes Senna e Sandra Francesca C. de Almeida expõem os resultados de uma pesquisa realizada com psicólogos escolares que atuavam, à época, na Rede Pública de Ensino do Distrito Federal.

No estudo, as autoras identificaram alguns entraves relacionados à atuação do psicólogo escolar, como a formação precária oferecida nos cursos de graduação, presença de ações tradicionais no exercício profissional, uso descontextualizado das teorias psicológicas da aprendizagem e do desenvolvimento, carência de cursos de especialização voltados à área da psicologia escolar/educacional e os reduzidos estágios na área ofertados durante a graduação, entre outros. Fatores que provocavam impactos na forma de atuar desses profissionais. Apesar disso, as autoras também destacam a existência de mudança de paradigmas, expressa pela conscientização dos profissionais da necessidade de reconfiguração de suas práxis, através do distanciamento de intervenções voltadas para classificação do sujeito. Assim, se por um lado, elas observam predomínio de ações tradicionais, como as da clínica psicológica levada ao contexto escolar, por outro, são otimistas ao perceberem maior conscientização e reflexão crítica dos profissionais em relação à necessidade de transformação de suas práticas no escolar, esboçada pela busca de aprimoramento.

Da Competência Teórica a Implicação Subjetiva: uma experiência de formação em psicologia escolar/educacional é o título do capítulo onze. Neste escrito, Cynthia Pereira de Medeiros relata sua experiência na formação e acompanhamento de estudantes de graduação, em estágios supervisionados na área da psicologia escolar/educacional. Tendo como objetivo possibilitar um 
contato do aluno com as instituições educativas de modo a compor uma visão crítica das problemáticas que emergem nesses espaços, a autora aponta três balizas fundamentais que contribuem na compreensão das queixas produzidas na e pela escola. Atrelada ao aporte teórico, menciona a concepção subjetiva que "nos obriga a deslocar do centro da discussão a questão do papel do psicólogo escolar/educacional para afirmar a radical singularidade do trabalho na área" (Medeiros, 2015, p. 265).

No capítulo doze, Claisy Maria Marinho Araujo e Sandra Francesca Conte de Almeida versam a respeito da Psicologia Escolar: recriando identidades, desenvolvendo competências. O eixo central da discussão gira em torno da identidade do psicólogo escolar, isto é, da falta de clareza percebida pelo profissional no que tange à sua práxis na escola, principalmente frente a outras áreas do conhecimento, quando inserido na equipes de trabalho. Face a essa dificuldade de reconhecimento de especificação "do que fazer", as autoras salientam a necessidade de operacionalizar ações mais ousadas e concretas que contribuam para a construção da identidade profissional do psicólogo escolar. Para elas, não basta apenas mostrar os desafios ou alertar, é preciso assumir a responsabilidade no processo formativo do psicólogo escolar. Nesse sentido, enfatizam a necessidade de se apresentar respostas a essa questão.

Todos os artigos que integram esse exemplar estão ancorados em uma perspectiva crítica e libertadora de psicologia escolar, incorporando pressupostos epistemológicos (como os citados anteriormente) capazes de subsidiar os afazeres dos profissionais ligados a este campo da psicologia, permitindo-lhes superarem as dicotomias e ideologias atrofiantes que, ao longo dos anos, enviesaram os trabalhos e intervenções propostos pela psicologia escolar. Ao invés de se deterem na enumeração de receitas estigmatizantes sobre o fazer do psicólogo escolar, os autores foram além, colocando a psicologia escolar a serviço da transformação social. Nesse sentido, o livro representa um instrumento valioso de reflexão e de parâmetro de atuação em psicologia escolar, apresentando experiências concretas e embasadas de forma crítica. Assim, recomenda-se a leitura deste manuscrito por psicólogos, educadores e demais interessados na temática.

\section{Sobre o autor}

Kairon Pereira de Araújo Sousa é psicólogo pela Universidade Estadual do Piauí UESPI, mestre em psicologia pela UFPI. Participa da linha de pesquisa Processos Psicossociais e sua Avaliação em Diferentes Contextos. Possui experiência profissional na área da psicologia social. kaironpereira@hotmail.com

Recebido em: 08/12/2017

Revisado em: 20/01/2018

Aceito em: 08/03/2018 